Coexistence and dynamics of overconfidence and strategic incentives

Katrien Bosquet; Peter de Goeij; Kristien Smedts

DEPARTMENT OF ACCOUNTANCY, FINANCE AND INSURANCE (AFI) 


\title{
Coexistence and Dynamics of Overconfidence and Strategic Incentives*
}

\author{
Katrien Bosquet ${ }^{\dagger} \quad$ Peter de Goeij ${ }^{\ddagger} \quad$ Kristien Smedts ${ }^{\S}$
}

\begin{abstract}
We present a two-stage model for the decision making process of financial analysts when issuing earnings forecasts. In the first stage, financial analysts perform a fundamental earnings analysis in which they are, potentially, subject to a behavioral bias. In the second stage analysts can adjust their earnings forecast in line with their strategic incentives. The paper analyzes this decision process throughout the forecasting period and explains the underlying drivers. Using quarterly earnings forecasts, we document that throughout the entire forecasting period financial analysts overweight their private information. At the same time, financial analysts behave strategically. They issue initial optimistic forecasts by strategically inflating their forecast. In their last revision, they become pessimistic and strategically deflate their earnings forecast, which creates the possibility of a positive earnings surprise. This analysis of the dynamics of the decision process provides empirical evidence on the coexistence of overconfidence and strategic incentives.
\end{abstract}

Keywords: Financial analysts, Earnings Forecasts, Overconfidence, Conflicts of interest.

JEL-classifications: G14; G17; G24

*We thank Bertrand Melenberg and seminar participants at Tilburg University for comments that improved the paper.

${ }^{\dagger}$ Catholic University of Leuven, AFI, Naamsestraat 69, 3000 Leuven, Belgium. Email: katrien.bosquet@econ.kuleuven.be, tel: (+) 32 (0)16 326675, fax: (+) 32 (0)16 326732.

${ }^{\ddagger}$ CentER, TILEC, Tilburg University, Department of Finance, P.O. Box 90153, 5000LE Tilburg, The Netherlands. Email: p.c.degoeij@tilburguniversity.nl, phone: (+) 31 (0)13 4662083, fax: (+) 31 (0)134662875.

$\S$ Catholic University of Leuven, AFI, Naamsestraat 69, 3000 Leuven, Belgium. Email: kristien.smedts@econ.kuleuven.be, tel: (+) 32 (0)16 326739, fax: (+) 32 (0)16 326732. 


\section{Introduction}

Studies of financial markets make assumptions concerning the behavior and decision process of market participants. The efficient market hypothesis postulates that all market agents are rational and value each security for its fundamental value or to the extent that some are not rational, the deviations from rational behavior are random (Schleifer, 2000). To the extent that agents are irrational systematically, the efficient market hypothesis assumes they are met in the market by rational arbitrageurs who eliminate any mispricing. Several studies however, show that arbitrageurs have limited resources in the market and therefore these systematic deviations from rationality remain present (see e.g. Kahneman and Riepe, 1998 and Odean, 1998). Among these market participants, financial analysts are an important source of information to the stock market in the valuation of firms (Schipper, 1991). They are often considered to be sophisticated investors, although they only provide advice, and are therefore an adequate group of market participants for research (De Bondt and Thaler, 1990). Sell-side analysts assimilate and process publicly available information, acquire private information and disseminate new information by issuing recommendations and earnings forecasts. Nevertheless, it is documented that analysts' earnings forecasts systematically deviate from the rational decision process (De Bondt and Thaler, 1990; Abarbanell, 1991; Brown, 1997; Easterwood and Nutt, 1999) and different explanations are put forward for these forecast inefficiencies. Broadly speaking, these systematic deviations from rationality in the decision making process can be assigned to a behavioral bias or conflicts of interest, which we will refer to as strategic incentives (Friesen and Weller, 2006).

The literature analyzing analysts' decision process is quite elaborate. Ramnath et al. (2008) make a thorough literature review on financial analysts and conclude that much of the analysts' decision process remains hidden in a black box. Recent studies analyzing the recommendations and earnings forecasts of financial analysts often focus on either the behavioral bias or the strategic bias, or put the behavioral opposed to the strategic bias, suggesting that only one of them can be present (see e.g. Chen and Jiang, 2006). Many studies have shown evidence of overconfidence (see e.g. Barber and Odean, 2001 and Hilary and Menzly, 2006) and many research has also provided empirical results on the existence of strategic incentives 
among financial analysts (see e.g. Dugar and Nathan, 1995 and Ljungqvist et al., 2007). However, the question whether both coexist in the analyst's decision process has yet to be answered. Therefore, the first contribution of this paper is the development of a two stage model for the decision making process of financial analysts allowing for the coexistence of a behavioral bias and a strategic bias. In the first stage of the model, financial analysts perform a fundamental analysis in which they combine public and private information to form their earnings forecast. During this first stage, analysts can be subject to a behavioral bias of which they are unaware. The assimilation of public and private information is modelled as a Bayesian expectation formation. This processing of information can be subject to a behavioral bias leading to suboptimal weighting (non-Bayesian) of the relevant pieces of information. Once the fundamental analysis is complete, a financial analyst can, in the second stage, consciously determine whether to deflate or inflate his forecast because of strategic reasons. The incorporation of strategic considerations is modelled as a multiplicative inflation or deflation of the initial forecast. The second contribution of this paper is that we use this two-stage model to provide empirical evidence that behavioral biases and strategic incentives coexist.

The best known behavioral bias is overconfidence. In the context of the financial market, which is characterized by a high degree of difficulty, low predictability and slow, noisy feedback, this bias is highly relevant (Fischoff et al., 1977; Deaux and Farris, 1977). Specifically, it is well known that analysts overestimate the probability that their personal assessment of the security's value is more accurate than the assessment of others (Barber and Odean, 2001). Therefore, when modelling the financial analyst's decision, we define, in accordance with Daniel et al. (1998), an overconfident investor as one who overestimates the precision of his private information signal.

With respect to the strategic conduct of analysts, the literature provides several conflicts of interest analysts are confronted with. On the one hand, financial analysts want to provide investors with accurate earnings forecasts. On the other hand, they are persuaded to please the management of the firms they cover, which can lead them to strategically change their forecast. When analyzing the strategic behavior of financial analysts it is imperative to understand, (i) what it is that pleases the management of a firm and (ii) why financial analysts are persuaded 
to strategically alter their earnings forecast estimate. Richardson et al. (2004) suggest that management wishes to sell stock on favorable terms after an earnings announcement, but wants beatable earnings targets before an earnings announcement. Since the 1990's firms' management is often compensated by stock options inducing an increased interest in the stock price among management. In this context, management prefers beatable targets before an earnings announcement. The reason is that there is an asymmetric response to earnings surprises. Skinner and Sloan (2002) find that the average response to negative earnings surprises is significantly larger in magnitude than the average response to positive earnings surprises. Bartov et al. (2000) show that firms which manage to beat or meet their earnings expectations enjoy an average quarterly return that is almost $3 \%$ higher. These empirical findings suggest that, in order to please management, financial analysts should be optimistic just after the earnings announcement, but be pessimistic just before the next earnings announcement.

As a third contribution to the literature, we perform an analysis of the dynamics and the underlying drivers of the decision process by investigating the strategic behavior of analysts throughout the forecasting period. This enables us to test whether the strategic behavior is in line with the management pleasing behavior described above. To our knowledge, we are the first to pursue an in depth analysis of the decision process over time. We compare the results of our two stage model applied to the first quarterly earnings forecasts as well as to the last quarterly earnings forecast revisions and confirm this pleasing behavior. We provide empirical evidence that financial analysts strategically inflate their initial forecast at the beginning of the forecasting period, but deflate their forecast in their final revision near the end of the forecasting period.

Other studies document why financial analysts are persuaded to strategically alter their earnings forecast. First, analysts are inclined to change their forecast, in order to please management of the stock being covered, because this leads to investment banking deals for their brokerage house. Financial analysts face a tradeoff between generating revenues for their employers' brokerage and investment banking businesses and their private career concerns (see e.g. Ljungqvist et al., 2007). Second, financial analysts are often dependent upon management to obtain additional information concerning the company (see e.g. Chen and Matsumoto, 
2006). Finally, a financial analyst's compensation is often tied to the trading commissions earned for their brokerage house (see e.g. Groysberg et al., 2008). Therefore, financial analysts are willing to adjust their forecast to raise commission fees and consequently their compensation.

The majority of existing empirical studies have found systematic analyst optimism relative to actual earnings outcomes (see for example O'Brian, 1988 and Abarbanell, 1991). In line with these findings, many studies document incentives which lead to strategic inflation of the forecast. Chen and Matsumoto (2006) find that managers provide more information to analysts with more favorable stock recommendations and Francis and Philbrick (1993) confirm that financial analysts report more optimistic earnings forecasts to please the management of the firms they cover. Dugar and Nathan (1995) show that financial analysts of brokerage firms, that provide investment banking services to a company, are optimistic, relative to other analysts, in their earnings forecasts and investment recommendations. It is only recently that researchers document systematic analyst forecast pessimism relative to actual quarterly earnings (see e.g. Brown, 2001 and Matsumoto, 2002). Several explanations in terms of strategic deflation of earnings forecasts have been put forward. Malmendier and Shanthikumar (2007) find that analysts with conflicting interests may distort recommendations upwards to trigger small-investor purchases and to please management, while they may distort earnings forecasts downwards shortly before the announcement, to allow management to beat the forecast. Markov and Tan (2006) also indicate that analysts have incentives to systematically underpredict earnings. When the expected earnings are at a lower level, they are kept beatable and they ensure a positive earnings surprise when the actual earnings are reported. If managers prefer beatable earnings forecasts, investment banking business as well as analysts' dependence on management for future information, can be used to pressure analysts to deflate their earnings forecast to placate management of the firm they cover.

Apart from management pleasing, financial analysts maximize their compensation by trying to increase the commission fees. Studies such as Chen and Jiang (2006) and Groysberg et al. (2008) suggest that analysts exaggerate information to increase trading volume. The increased volume renders higher trading commissions for the analysts. This exaggeration of information can be translated into both in- 
flation or deflation of the earnings forecast. However, Hong, Lim, and Stein (2000) show that positive news spurs more trading than negative news due to restrictions of short-selling. As an extension to the initial analysis, we add the strategic incentives of investment banking business and commission fees to the empirical model.

Our empirical results show that, initially, financial analysts are optimistic and strategically inflate their forecast. When issuing their last revision, however, they strategically deflate their forecast, creating an opportunity for a positive earnings surprise. For both forecasts, initial and last, financial analysts appear to be overconfident. During the entire forecasting period, financial analysts overweight their private information. Our analysis of the decision process throughout the forecasting period (dynamics) provides evidence of the coexistence of overconfidence and strategic incentives. The size of the behavioral bias is slightly smaller than the strategic alteration suggesting that strategic incentives are more economically relevant. The empirical results of the extended model confirm a positive relationship between affiliated analysts and strategic behavior. The empirical findings of the extended model are also consistent with Hong, Lim and Stein (2002) showing a positive relationship between commission fees and strategic inflation of the earnings forecast. To summarize, this paper contributes to the literature in three ways. The first contribution is the construction of a two stage model which allows for the coexistence of a behavioral bias and strategic incentives. As a second contribution the model is tested on a large dataset of earnings forecasts and empirical evidence is provided on the coexistence of overconfidence and strategic incentives. Finally, we perform the analysis throughout the forecasting period, showing a dynamic in analysts' decision process and explaining the underlying drivers. We provide evidence that is consistent with several explanations put forward in the existing literature.

The remainder of this paper is organized as follows. Section 2 elaborates on the decision making process. Section 3 presents the empirical model and the selected data. Section 4 discusses some descriptives on the data and section 5 discusses the estimation results. Next, section 6 provides some robustness checks. Finally, section 7 concludes. 


\section{The Two-Stage Analyst Decision Making Model}

When studying financial markets, a set of assumptions about the judgements, preferences and decisions of the participants in financial markets are needed. These judgements and decisions pertain to, amongst others, the character of earnings forecasts (Shefrin, 2008). In this section we introduce a two-stage model for financial analysts' decision making process when making their earnings forecasts. In the first stage financial analysts perform a fundamental analysis in which they combine both public and private information to come to their earnings forecast. During this first analysis, analysts can be influenced by behavioral biases of which they themselves are unaware. Once their fundamental analysis is complete, a financial analyst can, in the second stage, consciously determine whether to deflate or inflate his forecast because of strategic reasons. The assimilation of public and private information is modelled as a Bayesian expectation formation, similar to the model of Chen and Jiang (2006). This processing of information can be subjected to a behavioral bias leading to suboptimal weighting (non-Bayesian) of the relevant pieces of information. Finally, the incorporation of strategic considerations is modelled as a multiplicative inflation or deflation of the initial forecast.

Financial analysts perform an initial analysis in which they combine public and private information into an earnings forecast. Similar to Gervais and Odean (2001) and Chen and Jiang (2006), $a$ is defined as the actual announced earnings of a firm, which follows a diffuse zero-mean normal distribution; $c$ is defined as a statistic for all public information about $a$ :

$$
\begin{aligned}
c= & a+\varepsilon_{c} \\
& \varepsilon_{c} \sim N\left(0, \frac{1}{p_{c}}\right)
\end{aligned}
$$

with $p_{c}$ the precision of the public signal. Next, let $x$ be the analyst's private information about $a$ :

$$
\begin{aligned}
x= & a+\varepsilon_{x} \\
& \varepsilon_{x} \sim N\left(0, \frac{1}{p_{x}}\right) .
\end{aligned}
$$


with $p_{x}$ the precision of the analyst's private signal. The analyst's best conditional forecast of the actual earnings $(a)$ given its private information $(x)$ and its public information (c), using Bayes' rule, is as follows:

$$
E[a \mid x, c]=h x+(1-h) c
$$

where $h \approx \frac{p_{x}}{p_{x}+p_{c}} \in[0,1]$ is the precision of analyst's private signals relative to public information. When an analyst interprets publicly available information and weights his private information, he may be unconsciously subject to a behavioral bias. This could lead him to use a personal weighting scheme, that deviates from the correct rational scheme, and come up with a first stage earnings forecast $F$ :

$$
F=k x+(1-k) c
$$

with $k \in[0,1]$ the actual weight the analyst places on his private signal.

In the second stage, after the analyst makes his fundamental assessment of the company's earnings, strategic incentives might induce him to bias his forecast. Conflicts of interest may persuade the analyst to inflate or deflate his first assessment:

$$
f=s F=s[k x+(1-k) c]=s k x+(s-s k) c
$$

with $f$ the earnings forecast issued by the financial analyst and observed by the public. The strategic incentives are modeled by introducing a multiplicative factor $s \in[0,+\infty)$. As analysts are more likely to provide forecasts for stocks for which their true expectations are favorable and are reluctant to issue unfavorable investment information (McNichols and O'Brian, 1997), it is reasonable to assume that $s \in[0 ;+\infty)$. With $f$ the analyst's expectation about the actual earnings, the expected forecast error is defined as:

$$
\begin{aligned}
E[(f-a) \mid x, c] & \approx E[F E \mid x, c]=s k x+(s-s k) c-h x-(1-h) c \\
& =\frac{h}{k} c-\frac{h}{s k} f+(f-c)
\end{aligned}
$$

Rearranging allows for a clear separation between behavioral and strategic biases 
affecting an analyst's forecast and forecast error:

$$
\begin{aligned}
E[F E \mid x, c] & =\left(\frac{k-h}{k}\right)(f-c)+\left(\frac{h s-h}{s k}\right) f \\
& =\beta(f-c)+\gamma f
\end{aligned}
$$

The clear separation is reflected in the parameters $\beta$ and $\gamma$, where $\beta$ represents the behavioral bias and $\gamma$ represents the strategic alteration. When $\beta=\frac{k-h}{k} \neq 0$, then $k \neq h$, which indicates irrational (non-Bayesian) expectation formation. When $\gamma=\frac{h s-h}{s k} \neq 0$, then $s \neq 1$ and analysts inflate or deflate their forecast because of strategic incentives. To determine the order of magnitude of the behavioral bias and the strategic altering we actually need estimates of $\frac{k}{h}$ and $s$. Note that we do not make any statements about $k$ or $h$ itself. Only the ratio $\frac{k}{h}$ is identified and for our purposes it is sufficient. Therefore we extract $\frac{\widehat{k}}{h}$ from $\widehat{\beta}$ and $\widehat{s}$ from $\widehat{\gamma}$ in order to determine whether the systematic errors in analysts' earnings forecasts are attributed to the inefficient processing of information, or due to analysts' incentives, or both.

For a uniform interpretation of $s$ we split up the the data into negative and nonnegative earnings forecasts. To truthfully examine the decisions of analysts, we wish to maintain those forecasts for which analysts have put in all of their effort. Hayes (1998) concludes that the incentive to gather information are most intense for stocks that are anticipated to give strong performance. McNichols and O'Brian (1997) indicate that analysts drop stocks with unfavorable future prospects. To ensure a sample of forecasts with maximum coverage and processing of information, we drop the negative forecasts and only work with zero or positive earnings forecasts $^{1}$. Additionally, the behavioral process as well as the incentives can differ for negative and positive forecasts.

We are interested in $\frac{\widehat{k}}{h}$ and $\widehat{s}$ for drawing conclusions on behavioral biases and strategic incentives. $\frac{k}{h}$ and $s$ can not be estimated directly. Therefore $\beta$ and $\gamma$ from equation 7 have to estimated. Table 1 presents the possible outcomes for $\widehat{\beta}$ and $\widehat{\gamma}$ and the implication for $\frac{\widehat{k}}{h}$ and $\widehat{s}$. When $\widehat{\beta}>0$, then $\frac{\widehat{k}}{h}>1$ and analysts overweight their personal information relative to public information. When $\widehat{\beta}<0$, then $\frac{\widehat{k}}{h}<1$ and analysts underweight their personal information. When $\widehat{\gamma}>0$,

\footnotetext{
${ }^{1} \mathrm{~A}$ sample of only positive forecasts still implies a symmetric loss function of forecast errors.
} 
then $\widehat{s}>1$ and analysts inflate their earnings forecasts. When $\gamma<0$, then $\widehat{s}<1$ and analysts deflate their earnings forecasts because of strategic incentives.

\section{Table 1: Average FE}

This table presents the possible outcomes when equation (7) is estimated. We are interested in $\frac{\widehat{k}}{h}$ and $\widehat{s}$ for drawing conclusions on behavioral biases and strategic incentives. The table presents the possible outcomes for $\widehat{\beta}$ and $\widehat{\gamma}$ and the implication for $\frac{\widehat{k}}{h}$ and $\widehat{s}$.

\begin{tabular}{|c|c|c|c|}
\hline & $>0$ & $<0$ & $=0$ \\
\hline$\widehat{\beta}$ & $\begin{array}{c}\widehat{\frac{k}{h}}>1 \\
\text { overweight }\end{array}$ & $\begin{array}{c}\widehat{\frac{k}{h}}<1 \\
\text { underweight }\end{array}$ & $\begin{array}{l}\qquad \widehat{\frac{k}{h}}=1 \\
\text { rational weight }\end{array}$ \\
\hline$\widehat{\gamma}$ & $\begin{array}{l}\widehat{s}>1 \\
\text { inflate }\end{array}$ & $\begin{array}{c}\widehat{s}<1 \\
\text { deflate }\end{array}$ & $\begin{array}{c}\hat{s}=1 \\
\text { no alteration }\end{array}$ \\
\hline
\end{tabular}

\section{The Empirical Model}

To test the coexistence of a behavioral bias and strategic incentives, the following empirical model is used to test equation 7 :

$$
F E_{i k t}=\alpha+\beta D e v_{i k t}+\gamma f_{i k t}+\delta_{i} X_{i k t}+\varepsilon_{i k t}
$$

$F E_{i k t}$ is the forecast error made by the individual analysts. The forecast error is calculated as the difference between the analyst's forecast and the actual value of the earnings per share. Devikt is the deviation from the consensus and is determined as the difference between the analyst's forecast and the consensus forecast concerning the earnings per share. The consensus forecast proxies for available public information up to that point in time. The consensus forecast at time $t$ is calculated as the mean of all the analysts' estimates up to $t$, excluding the estimate of the analyst $i$, who makes his estimate at time $t$ (analogous to Chen and Jiang, 2006 and Zitzewitz, 2001). $f_{i k t}$ is the forecast of analyst $i$ on firm $k$ at time $t$. The forecast error, the deviation from consensus as well as the forecast the analyst makes are deflated by the share price. Following Clement (1999), Size of the covered firm $\left(\right.$ Size $\left._{k t}\right)$, general $\left(\right.$ TotExp $\left.p_{i t}\right)$ and firm specific experience $\left(\right.$ FirmExp $\left._{i k t}\right)$, two measures of task complexity $\left(\right.$ FirmCompl $_{i t}$ and IndCompl $\left._{i t}\right)$ and forecast age 
$\left(A g e_{i k t}\right)$ are added as control variables $\left(X_{i k t}\right)$. A full description of all variables and their summary statistics can be found in Table 8, in the Appendix. More information on the estimation technique for equation (8) can be found in Section 5.1 .

Analysts' quarterly earnings forecasts and stock price data are obtained from the Institutional Broker Estimate System (I/B/E/S) database, part of Thomson Financial. The earnings forecasts cover the period 1996 until 2006. The database is restricted to highly covered United States companies with a fiscal year end in December $^{2}$. The data set is stripped from errors and potential companies in difficulties ${ }^{3}$. Financial analysts issue earnings forecasts for a certain company in a certain quarter and, as mentioned earlier, only non negative earnings forecasts are kept in the data set $^{4}$.

Financial analysts issue an earnings forecasts for a certain company in a certain quarter but they can make a revision during this quarter. Pursuing an in depth analysis of the decision process throughout the forecasting period, we compare first forecasts with last revisions. Consequently two data sets are created, one where only the first forecast is kept and one where only the last revision is kept. The First Forecast sample contains 322,123 earnings forecasts, issued by 6,736 analysts on 2,773 companies. The First Forecast sample contains the first forecast when analysts make revisions during the quarter and the sample contains the first and only forecasts when analysts make no revisions in the forecasting period ${ }^{5}$. The Last Revision sample contains 60,047 earnings forecasts, issued by 4,148 analysts on 747 companies. The presence of forecast revisions provides a measure of how closely analysts follow the stock that they cover (Green et al., 2007). Therefore,

\footnotetext{
${ }^{2}$ High coverage is ensured by demanding a minimum average coverage of three analysts, deleting firms which have an average market capitalization below $\$ 100$ million and deleting companies for which the average market price is below $\$ 5$.

${ }^{3}$ Earnings forecasts released after actual earnings have been reported, are deleted. Observations of companies, reporting later than 45 days after the last day of the end of the quarter, are eliminated. It is determined by law that quarterly filings must be filed with the SEC within 45 days subsequent to the end of each quarter.

${ }^{4}$ Deleting negative forecasts implies a reduction of the dataset of $11 \%$ from 362,040 to 322,123 quarterly forecasts in the First Forecast sample. Deleting negative forecasts implies a reduction of the dataset of $12 \%$ from 68,270 to 60,047 quarterly forecasts in the Last Revision sample.

${ }^{5} \mathrm{I} / \mathrm{B} / \mathrm{E} / \mathrm{S}$ calls up the majority of the analysts asking whether they want to update their forecast. An analyst without a revision has consciously chosen to issue and stick to his first forecast.
} 
the difference in sample size suggests that many analysts focus mainly on a few companies, only issuing revisions for those.

\section{Data Descriptives}

The majority of past empirical studies finds systematic analyst optimism relative to actual earnings outcomes (see e.g. O'Brian, 1988 and Abarbanell, 1991). It is only recently that researchers document systematic analyst forecast pessimism relative to actual quarterly earnings (see e.g. Brown, 2001 and Matsumoto, 2002). Brown (2001) shows that the mean earnings surprise, which is the difference between the analyst's forecasted earnings and the actual announced earnings, has shifted from small positive to small negative during the 16 years of 1984 until 1999. Table 2 provides an overview of the average forecast error (FE) over time for the First Forecast sample as well as for the Last Revision sample. From the First Forecast sample it becomes clear that average optimism turns into average pessimism after 2002. Turning to the Last Revision sample we notice that the average FE is always negative, implying that financial analysts are pessimistic when issuing their final revision. The difference between the first forecast and the last revision makes clear that financial analysts are optimistic (less pessimistic) when issuing their initial forecast but tend to become pessimistic (more pessimistic) when making their final revision.

A graphical visualization of Table 2 can be found in Figure 1. The first forecasts, issued by financial analysts, clearly show how analysts become less optimistic around 1999 and even pessimistic after 2002. This is in line with economic events such as the burst of the dot-com bubble and the introduction of new analyst regulation in 2002 as a reaction to a series of accounting scandals. The last revision of financial analysts follows the same general trend over time as the first forecasts but is always negative and lower than the first forecast. These preliminary descriptives are in line with findings from Markov and Tan (2006), who indicate that analysts have incentives to systematically underpredict earnings. Underpredicted earnings set beatable targets for firms' management. The positive earnings surprise following the earnings announcement has a positive impact on the market price. Also, the descriptives are consistent with Richardson et. al. (2004), who suggest that analysts tend to issue optimistic forecasts early and slightly pessimistic forecasts 


\section{Table 2: Average FE}

This table presents the average FE (forecast error) for each year from 1996 until 2006. The average FE is reported for both the First Forecast sample and the Last Revision sample. The last column shows the difference between the average FE for the First and Last forecast.

\begin{tabular}{l|rrr} 
& First Forecast & Last Revision & Difference \\
\hline 1996 & 0.0070 & -0.0116 & 0.0186 \\
1997 & 0.0034 & -0.0115 & 0.0149 \\
1998 & 0.0188 & -0.0108 & 0.0296 \\
1999 & -0.0002 & -0.0209 & 0.0206 \\
2000 & 0.0004 & -0.0221 & 0.0224 \\
2001 & 0.0260 & -0.0153 & 0.0413 \\
2002 & 0.0034 & -0.0047 & 0.0082 \\
2003 & -0.0098 & -0.0237 & 0.0139 \\
2004 & -0.0149 & -0.0283 & 0.0134 \\
2005 & -0.0133 & -0.0217 & 0.0084 \\
2006 & -0.0115 & -0.0309 & 0.0194 \\
\hline
\end{tabular}

late in the forecast period.

Figure 1: Average FE of First Forecast and Last Revision

The figure shows the average FE for the First Forecast and the Last Revision over time. The time period covers 1996 until 2006.

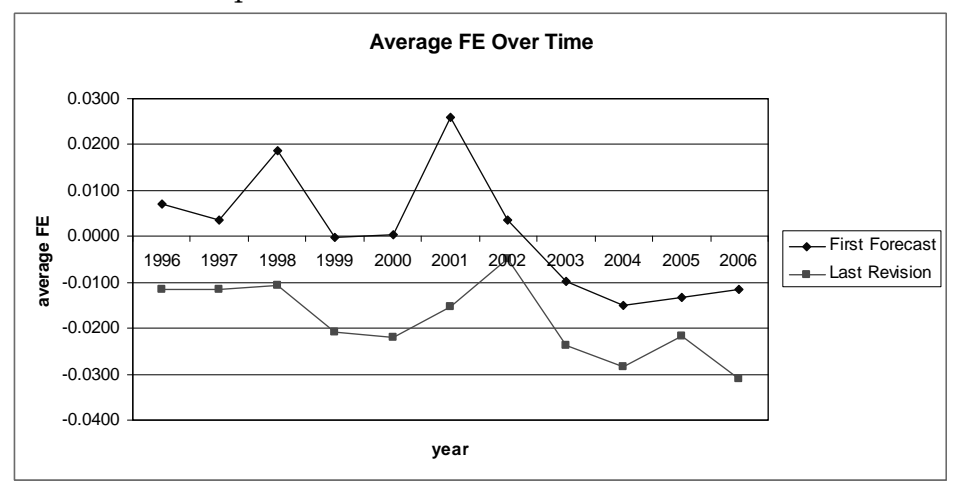

The descriptives already suggests that financial analysts are, in some periods of time more than others, optimistic in their initial forecast. Their last revision, on the contrary, is systematically pessimistic. These preliminary findings are consistent with management pleasing behavior. In the next section, using our empirical model, we take a closer look at the decision process and analyze the underlying drivers throughout the forecasting period. 


\section{Empirical Results}

\subsection{Main Findings}

Both data sets contain financial analysts' earnings forecasts for a particular stock at a certain point in time. This three way panel possibly contains certain unobserved effects. Petersen (2008) concludes that OLS with clustered standard errors (if necessary multiway) is the best estimation method for panel data with unobserved effects. Following the suggestions of Petersen (2008) and comparing clustered standard errors, in each dimension or multiple dimensions, with White (1984) standard errors, we conclude that standard errors clustered by industry are sufficient ${ }^{6}$. Thomson Financial uses a proprietary classification scheme to categorize companies into homogenous groups according to business lines. Companies are aggregated at three different levels: sector, industry and group. Thompson (2006), as well as Petersen (2008), emphasize that for obtaining unbiased standard errors, a sufficient number of clusters are required. The division into groups results in 211 clusters containing similar business lines. Moreover a firm fixed effects estimation is used. The reason is not only to allow a more efficient estimation of parameters but also to control for a possible endogeneity issue. Several studies (see e.g. Healy and Wahlen, 1999) document the presence of earnings management in firms. When a forecast ends up below the actual reported earnings this can be attributed to earnings management by the firm covered or by strategic deflation by the analyst. A firm fixed effects estimation eliminates this endogeneity issue. Consequently, to estimate equation (8) we use firm fixed effects with clustered standard errors by 211 industry groups. The estimation results for regression (8), applied to the First Forecast sample and the Last Revision Sample, are presented in Table 3.

Concerning the First Forecast sample, the regression results present a positive significant $\widehat{\beta}$ at the $1 \%$ significance level. $\beta$ is the parameter associated with the covariate $D e v_{i k t}$ and can be found in Table 3 on the third row. With $\widehat{\beta}$ significantly higher than zero, it follows from Table 1 , that $\frac{\widehat{k}}{h}>1$. Following

\footnotetext{
${ }^{6}$ Standard errors were clustered in one dimension by firm, analyst, quarter and industry. A time, firm and industry effect could be detected. Afterwards standard errors were clustered in two dimensions by firm-quarter, industry-quarter and firm-industry. It became clear that the industry effect was sufficient because standard errors did not change by adding an additional dimension.
} 


\section{Table 3: Estimation Results}

This table presents estimation results for equation (8). The second and third column show the coefficient estimates and t-values, respectively, using analysts' first earnings forecast. The third and fourth column represent the coefficient estimates and t-values, respectively, using analysts' last earnings review. For both regressions firm fixed effects is used with clustered standard errors by industry. These clustered standard errors are White (1984) standard errors adjusted to account for possible correlation within a cluster, i.e. industry. The earnings forecast data is obtained from I/B/E/S. ***,*** indicate significance at the $10 \%, 5 \%$ and $1 \%$ level, respectively. Coefficient estimates are multiplied by 1000 to facilitate readability.

The last two rows of this Table presents estimation results for the weighting factor $\frac{k}{h}$ and the strategic factor $s$, defined in equation (7). To determine the standard errors of the weighting and strategic factor the delta method is used. For both factors the two sided hypothesis test of whether they are significantly different from 1 is performed. $* * *, * * *$ indicate significance at the $10 \%, 5 \%$ and $1 \%$ level, respectively.

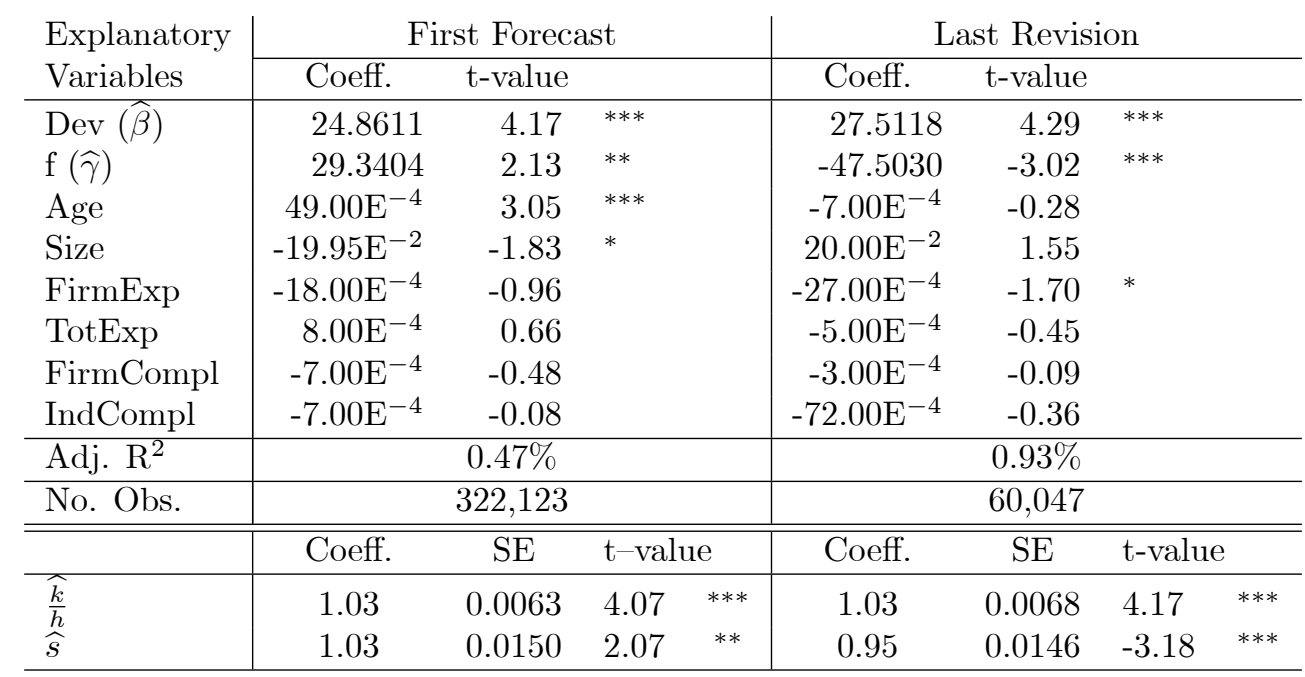

the definition of Daniel et. al. (1998), we interpret this overweighting of the precision of private information as overconfidence. For the First Forecast sample, $\widehat{\gamma}$ is positive significant as well which means that there is a strategic inflation of the initial forecast. $\gamma$ is the parameter associated with the covariate $f_{i k t}$ and can be found in Table 3 on the fourth row. The regression results partly confirm the descriptives: financial analysts are optimistic when issuing their initial forecast. This optimism stems from overconfidence and strategic inflation of their forecast.

With regard to the Last Revision sample, both $\widehat{\beta}$ and $\widehat{\gamma}$ are significantly different from zero. $\widehat{\beta}$ remains positively significant indicating the presence of overconfidence. Financial analysts remain overconfident about the precision of their private information. $\widehat{\gamma}$, however, becomes negatively significant implying that financial 
analysts deflate their forecast for strategic reasons. Off course due to mathematical construction, the coefficient $\widehat{\gamma}$ on itself cannot reveal anything about the order of magnitude of the deflation. When issuing their final revision, financial analysts remain overconfident but consciously and strategically decide to deflate their forecast.

The construction of the model in equation (7) identifies a weighting factor $\frac{k}{h}$ and a strategic factor $s$. Formulating estimates and standard errors on the two factors allows us to compare the behavioral and strategic bias in magnitude. As $\gamma$ contains both the weighting and strategic factor, a conclusion about the magnitude of the strategic change cannot be made from $\gamma$ itself. We calculate estimates and standard errors for $\frac{k}{h}$ and $s$. A two sided t-test determines whether the factors are significantly different from one. The weighting factor $\frac{\widehat{k}}{h}$ is significantly larger than 1 at the 1\% level for both the First Forecast and the Last Revision sample. Financial analysts overweight the precision of their private information by about $3 \%$ when issuing their initial forecast and when making their last revision. The strategic factor $\widehat{s}$ is significantly different from 1 in the First Forecast sample and the Last Revision sample. However, for the initial forecast we find an $\widehat{s}$ larger than 1 while for the last revision this $\widehat{s}$ is smaller than 1 . Financial analysts strategically inflate their initial forecast by $3 \%$ while they strategically deflate their final revision by about $5 \%$.

We conclude that financial analysts remain overconfident about the precision of their private information throughout the forecasting period. This is in line with the assumption of an unconscious behavioral bias. At the same time analysts behave strategically, in a fashion which is in line with what pleases management of covered stocks. To maximize their own compensation, often consisting out of stock options, management of a firm prefers optimistic forecasts after an earnings announcement and beatable targets just before an earnings announcement. These empirical results confirm that financial analysts deliberately inflate their initial forecast while they consciously deflate their last revision. Therefore, they spur on investors, by issuing initial optimistic forecasts, to buy the stock and consequently driving up the price which is favorable for management of the covered stock. By issuing pessimistic last revisions they set beatable targets for the management creating the opportunity to obtain a positive earnings surprise. This positive earnings 
surprise also drives up the stock price after the earnings announcement. The reason why analysts engage in this pleasing behavior can be attributed to two possible underlying causes. On the one hand financial analysts bow to investment banking pressure (Ljungqvist et al., 2007) or the dependence on management for future information and therefore alter their forecast. On the other hand, management of covered firms engage in earnings guidance, releasing specific amounts and content of information and consequently guide financial analysts to the desired earnings level. While analysts are overconfident throughout the forecasting period, our empirical results show that the strategic behavior of analysts changes significantly throughout the forecasting period.

In the literature of financial analysts, researchers use the first (see e.g. Francis and Philbrick, 1993) or the last (see e.g. Byard and Shaw, 2003) quarterly or annual earnings forecast, often on a non-motivated basis. Our empirical findings indicate that analysts' decision making differs in the first forecast or the last. The choice of the first or last forecast is therefore not innocent. Depending on the purpose of a study the first or last forecast might be more appropriate (or both as a robustness).

\subsection{Closely Monitored Stocks}

Studying the dynamics within the forecasting period implies the comparison of two data samples who differ in size. The First Forecast sample contains 322,123 observations while the Last Revision sample only has 60,047 observations. The First Forecast sample is much larger because it contains analysts who issue only one forecast on a certain stock. When taking a closer look at both samples it becomes clear that the difference in size is due to a significantly smaller amount of companies being followed in the Last Revision sample. In the First Forecast sample analysts cover 2,773 companies while in the Last Revision sample analysts only cover 747 companies. These differences in sample size indicate that the majority of analysts follows a limited number of stocks closely, while they keep track of other companies in a more superficial manner. The closely monitored companies get initial forecasts and revisions while the other companies only get an initial forecast.

The presence of forecast revisions provides a measure of how closely analysts follow the stock that they cover (Green et al., 2007). One could argue that the behav- 
ior towards stocks which are closely monitored could be different from behavior towards stocks which are followed only in a superficial manner. Therefore we perform a segmentation of the First Forecast sample. Up until now this First Forecast sample contained the first forecast of all analysts. Now we divide this group into the analysts who only issue one forecast during the entire quarter (we refer to this as the Single Issue sample) and financial analysts who issue a revision during the quarter (we refer to this as the First of Revision sample). In the First of Revision sample we evaluate the first forecast of the analysts who are also in the Last Revision sample. In addition, this segmentation provides a comparison between the first forecast and the last revision under similar sample size conditions. Table 4 shows the estimates of $\frac{k}{h}$ and $s$ for the Single Issue sample and the First of Revision sample.

\section{Table 4: Subsamples: Single Issue and First of Revision}

This table presents estimation results for the weighting factor $\frac{k}{h}$ and the strategic factor $s$, defined in equation (7). The estimates of $\beta$ and $\gamma$ can be found in Table 9, in Appendix. To determine the standard errors of the weighting and strategic factor the delta method is used. For both factors the two sided hypothesis test of whether they are significantly different from 1 is performed. *,**,*** indicate significance at the $10 \%, 5 \%$ and $1 \%$ level, respectively.

Weighting and Strategic Factor

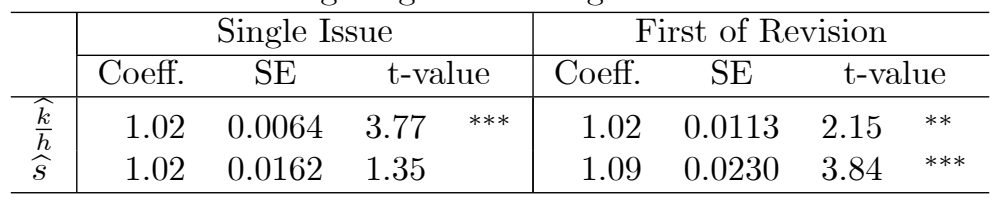

The results from Table 4 show, for the Single Issue sample, a $\frac{\widehat{k}}{h}$ which is significantly larger than 1 but an $\widehat{s}$ which is not significantly different from 1 . When analysts follow up on a firm in a superficial manner and issue only one forecast, they are overconfident but not strategic. For the First of Revision sample, both $\frac{\widehat{k}}{h}$ and $\widehat{s}$ are significantly larger than 1 . The few companies, which are closely followed by financial analysts, are the companies for which financial analysts engage in strategic behavior. The overweighting of private information in both subsamples provides additional evidence for overconfidence as an unconscious process.

We are aware that the First of Revision sample could be subject to a selection bias. This sample is constructed based on a post-factum event: a revision at the end of the quarter is used as a criteria to select analysts at the beginning of the 
quarter. Our main goal is to provide sufficient empirical evidence on the coexistence of overconfidence and strategic incentives. Therefore we wish to compare the first forecast to the last revision under similar sample size conditions. Above we accomplished similar sample size by looking at the first forecast of analysts who issue a revision. To address the problem of a possible selection bias we now draw a random sample of 60,047 observations from the First Forecast sample. The results remain consistent with previous findings: financial analysts are overconfident and strategically inflate their initial forecast. Estimation results can be found in Table 13 in the Appendix.

\subsection{The Extended Model}

To further investigate the coexistence and dynamics of overconfidence and strategic behavior and the validity of the two-stage model, we add several explanatory variables to equation (8). So far we illustrate that financial analysts strategically inflate their first forecast, but deflate their last revision. Earlier research (see e.g. Dugar and Nathan, 1995 and Ljungqvist, 2007) shows that affiliated analysts are more eager to please management. Therefore we add investment banking business (IB) as a strategic incentive to the model. We expect these affiliated analysts to inflate their initial forecast more severely and deflate their last revision more explicitly. A financial analyst is perceived as affiliated when the brokerage house, he or she works for, has assisted as underwriter in a public offering of the company, for which the analyst is following the stock. The window of affiliation is five years (following Chen and Jiang, 2006), centered around the moment of the registration with the SEC of the public offering. To determine the affiliation of financial analysts, all public offerings done by US companies with a registration date between July 1996 and December 2007 are taken into account. The data related to these offerings are obtained from Westlaw Business, part of Thomson Financial.

As mentioned earlier, analysts' compensation is often tied to generated trading commissions. It has been argued that analysts will exaggerate their forecast to induce more trading and consequently higher trading volumes to maximize their compensation. Hong, Lim, and Stein (2000) show that positive news spurs more trading than negative news, therefore we expect a positive relation between trading volume and the strategic component $s$ : financial analysts concerned with their 
compensation inflate their forecast to induce higher trading volumes. Higher commissions are easier to obtain when a shift in information occurs for a stock which is known to have a high trading volume. Trading volume is the average daily number of shares traded the previous quarter multiplied by the average daily price of the previous quarter, and will be used to proxy for the commission incentive. Trading volume data is acquired from CRSP and is expressed in millions of dollars.

Daniel et. al. (1998) show that investors view themselves as more able to value securities than they actually are. Each investor is overconfident in the sense that if he receives a signal, he overestimates its precision. Not only this static overconfidence has been investigated but also the dynamics of overconfidence has been studied. Gervais and Odean (2001) illustrate how analysts overestimate their ability after a series of successful forecasts because of a biased learning process. Hilary and Menzly (2006) confirm the dynamics of overconfidence by pointing out that a previous thriving track record leads to more bold forecasts and consequently to more forecast errors. In an attempt to not only provide evidence for the static overconfidence but also for the dynamics, we add a track record variable (TR) defined similarly to the track record variable from Chen and Jiang (2006). TR $\mathrm{TR}_{i k t}$ measures the frequency of the analysts' earnings forecast being more accurate than the consensus forecast up until time $t$ for firm $k$.

$$
T R_{i k t}=\frac{1}{N_{i k t}} \sum_{j=1}^{N_{i k t}} \operatorname{sign}\left(\left|F E_{-} C_{\text {ons }} s_{i k j}\right|-\left|F E_{i k j}\right|\right)
$$

where $N_{i k t}$ is the number of realized forecasts made by analyst $i$ on firm $k$ up to time $t$ and FE_Cons $s_{i k j}$ is the forecast error of the consensus, and where $\operatorname{sign}(\cdot)$ is the sign function defined as:

$$
\operatorname{sign}(.)=\left\{\begin{array}{c}
1 \text { if }\left|F E_{-} C_{\text {Cons }} i_{i k j}\right|-\left|F E_{i k j}\right|>0 \\
0 \text { if }\left|F E_{-} C_{\text {Cons }}\right|-\left|F E_{i k j}\right|=0 \\
-1 \text { if } \mid F E_{-} \text {Cons }_{i k j}|-| F E_{i k j} \mid<0
\end{array}\right.
$$

Based on previous empirical results (see e.g. Hilary and Menzly, 2006), we expect a positive relation between the past track record of an analyst and overconfidence $\left(\frac{k}{h}>1\right)$.

Zitzewitz (2001) and Chen and Jiang (2006) provide empirical evidence that low 
ability analysts exaggerate their private information because of reputation concerns. This incentive exists because the market uses information in forecast deviations to form beliefs about an analyst's ability. On average, high ability analysts have viewpoints that are more different from the consensus. In an attempt to mimic these high ability analysts, low ability analysts overweight the precision of their private information. The exaggeration of the news content of their private information leads to larger forecast deviations, a pattern typical of high ability analysts. Since investors form perceptions about an analyst's ability from his track record (Chen, Francis and Jiang, 2005), the mimicking hypothesis also predicts a positive relation between overweighting and track records. The overconfidence and mimicking hypothesis differ in their prediction about the relation between ability and overweighting. The overconfidence hypothesis predicts no relation, after controlling for track records, while the mimicking hypothesis predicts a negative relation once track records are controlled for. To determine the underlying driver of the overweighting behavior, we add an ability measure to the model. According to the mimicking hypothesis the less able analysts mimic the high ability analysts to increase perceived reputation. Michaely and Womack (1999) argue that the analyst's perceived external reputation is one of the major factors determining an analyst's compensation and Stickel (1992) shows that the annual Institutional Investor All-America Research Teams poll is perhaps the most significant external influence driving analyst compensation. Therefore, we use the Institutional Investor All-America Research Team poll as an ability or perceived external reputation measure. We define a Star dummy based on this yearly prestigious ranking, published in the October edition of Institutional Investor (see also Hong and Kubic, 2003 and Sorescu and Subrahmanyam, 2006). Financial analysts identified as Star analysts are assumed to be high ability analysts. The Star dummy equals 1 when the analyst was elected a star past October and zero otherwise ${ }^{7}$. The summary statistics and a description of all added variables can be found in Table 10 in the Appendix.

\footnotetext{
${ }^{7}$ Stickel (1992) shows that financial analysts, who are elected a star or who will become a star, perform better than other financial analysts, who have never been elected or will never become a star. The star status is awarded in October based on the performance of the previous year. One could argue to use the year previous to the awarded star status as the ability measure. Changing the definition of Star does not impact our empirical findings.
} 
The extended regression model to be tested looks as follows:

$$
\begin{aligned}
F E_{i k t}= & \alpha+\beta_{0} \operatorname{Dev}_{i k t}+\beta_{1}\left(\operatorname{Dev}_{i k t} \times T R_{i k t}\right)+\beta_{2}\left(\text { Dev }_{i k t} \times \text { Star }_{i t}\right) \\
& +\gamma_{0} f_{i k t}+\gamma_{1}\left(f_{i k t} \times I B_{i k t}\right)+\gamma_{3}\left(f_{i k t} \times T V o l_{k t}\right)+\delta_{i} X_{i k t}+\varepsilon_{i k t}
\end{aligned}
$$

The estimation results of equation (10) can be found in Table 11 in Appendix. Analyzing $\frac{k}{h}$ and $s$ shows overconfidence throughout the forecasting period, strategic inflation of first forecasts and deflation of last revisions. To determine how the weighting factor and the strategic factor evolve for changes in the added covariates, we perform a ceteris paribus analysis. In the extended model, the weighting factor $\frac{k}{h}$ and the strategic component $s$ are defined as follows:

$$
\begin{aligned}
\widehat{\left(\frac{k}{h}\right)_{t}} & =\frac{1}{1-\left(\widehat{\beta}_{0}+\widehat{\beta}_{1} T R_{i k t}+\widehat{\beta}_{2} S t a r_{i k t}\right)} \\
\widehat{s}_{t} & =\frac{1-\left(\widehat{\beta}_{0}+\widehat{\beta}_{1} T R_{i k t}+\widehat{\beta}_{2} S t a r_{i k t}\right)}{1-\left(\widehat{\beta}_{0}+\widehat{\beta}_{1} T R_{i k t}+\widehat{\beta}_{2} S t a r_{i k t}\right)-\left(\widehat{\gamma}_{0}+\widehat{\gamma}_{1} I B_{i k t}+\widehat{\gamma}_{2} T V o l_{i k t}\right)}
\end{aligned}
$$

The weighting factor and the strategic factor are evaluated at specific values of the added covariates. When, for example, Star changes from 0 to 1 , the other covariates are kept at their mean value.

Figures 2 and 3 depict the, ceteris paribus, impact of $T R$ and Star on the weighting factor and the impact of $I B$ and $T V o l$ on the strategic factor. The values of $\frac{\widehat{k}}{h}$ and $\widehat{s}$ for each covariate can be found in Table 12 in Appendix. With regards to the strategic incentives, the relations of $I B$ and Tvol with $\widehat{s}$ are as predicted by the literature. Affiliated analysts are somewhat more optimistic in their first forecast and a bit more pessimistic in their last revision, however not significantly. When trading volume increases and the possibility for a higher commission fee increases, financial analysts become, not significantly, more optimistic. The results for the drivers of the overweighting behavior, $T R$ and Star, are inconclusive. We find no significant relation between an analyst's track record and overweighting behavior. In addition, the analysis only shows a significant negative relation between ability (Star) and overweighting for the Last Revision sample. Therefore, we don't confirm the mimicking hypothesis but neither do we confirm the presence of dynamic 


\section{Figure 2: Weighting factor}

This figure shows the changes in the weighting factor for specific values of TR and Star. Star is evaluated at the values 0 and 1 because it is a dummy variable. $T R$ is evaluated at the minimum, 1st quantile, mean, 3rd quantile and the maximum. When one covariate changes values of the others are kept at their mean value.

First Forec ast TR

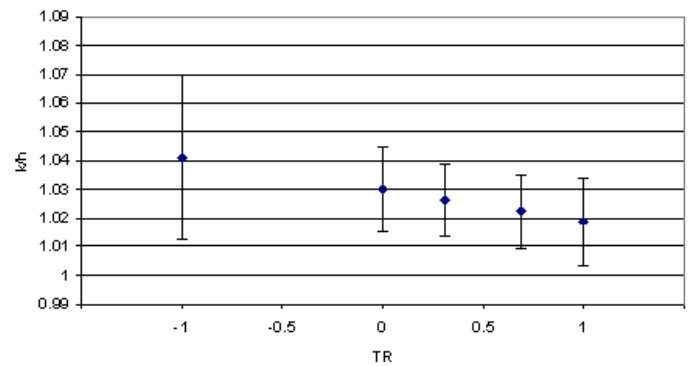

First Forecast: Star

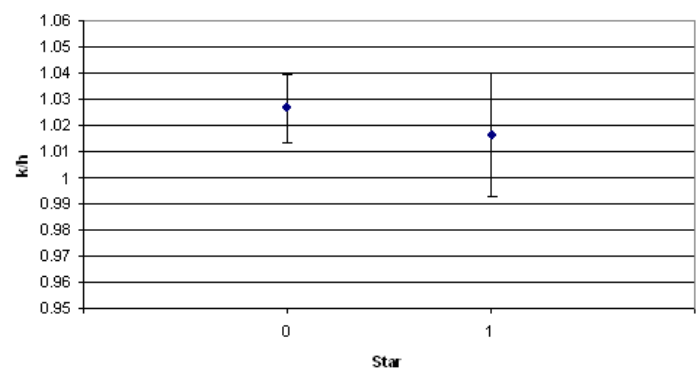

Last Revision: TR

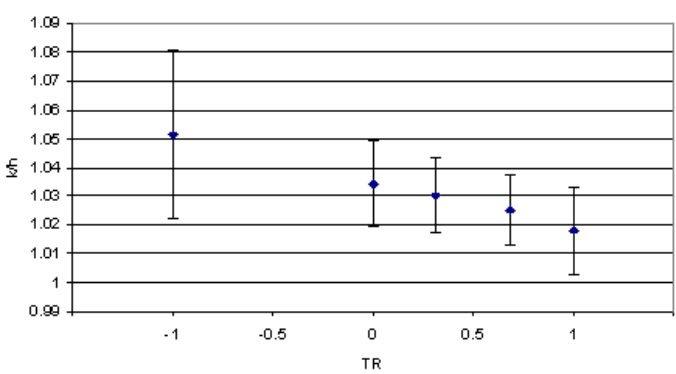

Last Revision: Star

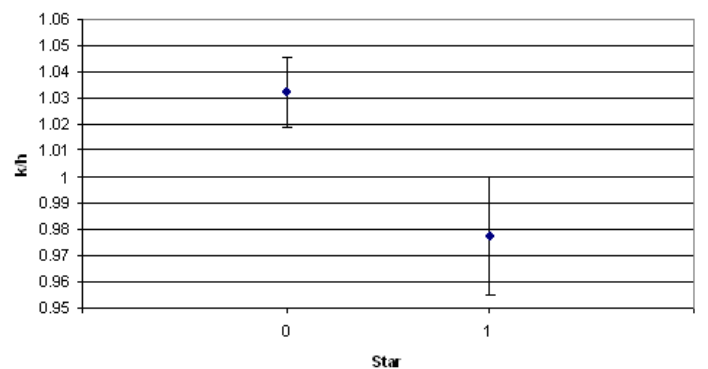

overconfidence. We only confirm a static overconfidence: each investor is overconfident in the sense that if he receives a signal, he overestimates its precision (Daniel et al.,1998).

\section{Robustness Checks}

\subsection{Alternative Consensus Measure}

When testing our model, expressed in equation (7), the public information is proxied by a consensus measure. In previous results this consensus has been calculated as the mean of the earnings forecasts, pertaining to the same quarter, previous to the analysts' own forecast. As a robustness check we also calculate the median consensus and we obtain similar results. Estimation results are reported in Table 14 in the Appendix. 


\section{Figure 3: Strategic factor}

This figure shows the changes in the strategic factor for specific values of $I B$ and $T V o l$. $I B$ is evaluated at the values 0 and 1 because it is a dummy variable. $T V o l$ is evaluated at the minimum, 1st quantile, mean, 3rd quantile and the maximum. When one covariate changes values of the others are kept at their mean value.

First forec ast IB

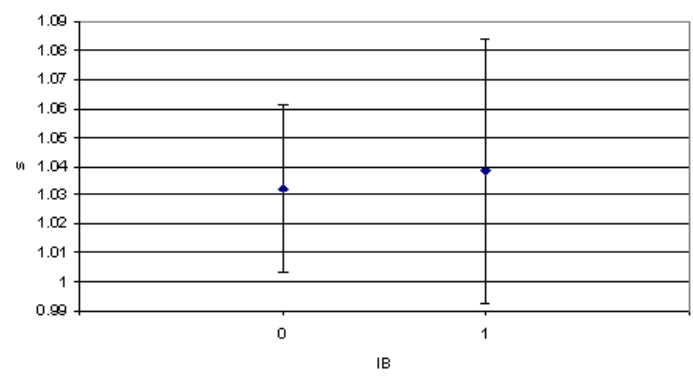

First Forecast: TVOL

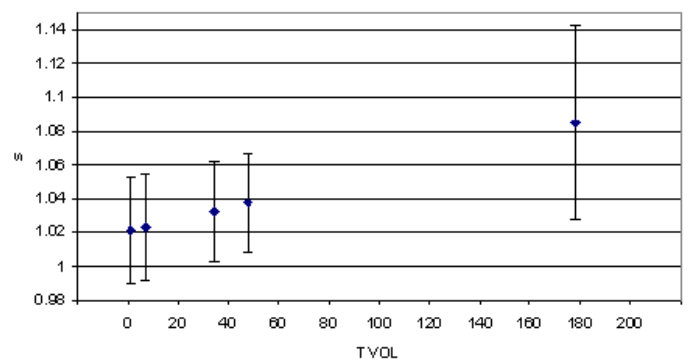

Last Revision IB

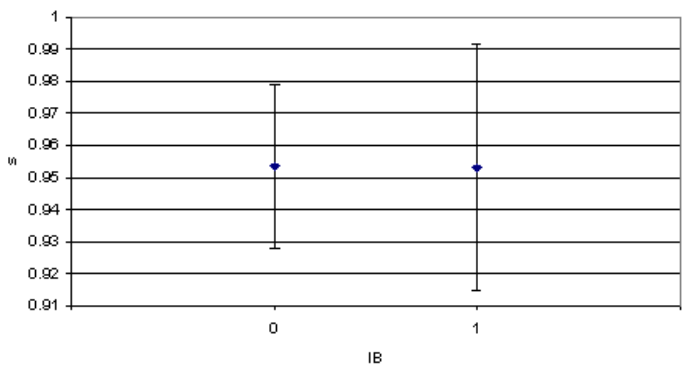

Last Revision: TVOL

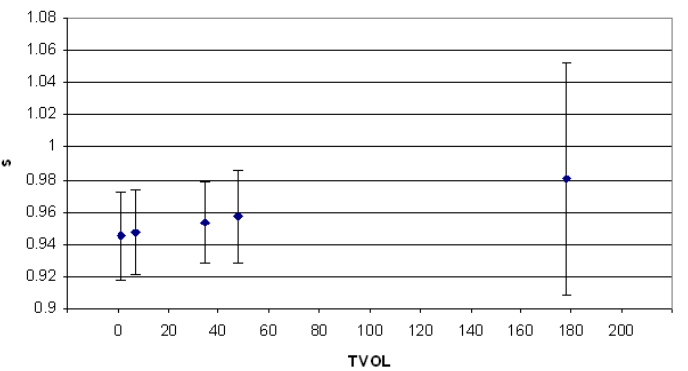

\subsection{Regulatory Impact: 2002}

Figure 1 reveals that, after 2002, analysts become pessimistic in their first forecast. Even though the last revision is still below the first forecast, the difference between them appears to be much smaller. In 2002, after the dot-com bubble burst, it was clear that financial analysts were not free from conflicts of interest and their recommendations and earnings forecasts far from unbiased. On May 10, 2002 the SEC approved the NYSE Rules 351 and 472 and the NASD Rule 2711 which implemented basic reforms to pursue the objectivity of the financial analyst's research. This regulatory change could be a trigger for a change in behavior. Consequently, we analyze the decision process for two separate time periods: the pre 2002 and the post 2002 period. The cut off point is the second quarter of the year 2002 because this contains the month of May. The pre period runs from January 1996 until April 2002 and the post period runs from April 2002 until December 2006. 


\section{Table 5: Evaluation Pre and Post 2002}

This table presents estimates for the weighting factor $\frac{k}{h}$ and the strategic factor $s$ for two periods of time: pre 2002 and post 2002. The results are presented for both the First Forecast sample and the Las Revision sample. The estimates of $\beta$ and $\gamma$ can be found in Table 15, in Appendix. To determine the standard errors of the overweighting and inflation factor the delta method is used. For both factors the two sided hypothesis test of whether they are significantly different from 1 is performed. *,**,*** indicate significance at the $10 \%, 5 \%$ and $1 \%$ level, respectively.

\begin{tabular}{|c|c|c|c|c|c|c|c|c|c|}
\hline & \multicolumn{9}{|c|}{ Weighting and Strategic Factor } \\
\hline & & \multicolumn{4}{|c|}{ First Forecast } & \multicolumn{4}{|c|}{ Last Revision } \\
\hline & & Coeff. & SE & t-va & & Coeff. & SE & t-val & \\
\hline \multirow{4}{*}{ PRE 2002} & $\widehat{k}$ & 1.04 & 0.0114 & 3.08 & $* * *$ & 1.03 & 0.0075 & 4.45 & $* *$ \\
\hline & $\widehat{s}$ & 1.06 & 0.0218 & 2.59 & $* * *$ & 0.95 & 0.0133 & -3.89 & $* * *$ \\
\hline & No. Obs. & \multicolumn{4}{|c|}{154,210} & \multicolumn{4}{|c|}{26,607} \\
\hline & & Coeff. & $\mathrm{SE}$ & \multicolumn{2}{|c|}{ t-value } & Coeff. & $\mathrm{SE}$ & \multicolumn{2}{|c|}{ t-value } \\
\hline \multirow{3}{*}{ POST 2002} & $\widehat{k}$ & 1.03 & 0.0089 & 2.83 & $* * *$ & 1.03 & 0.0085 & 3.37 & $* * *$ \\
\hline & & 1.02 & 0.0250 & 0.72 & & 0.96 & 0.0278 & -1.58 & \\
\hline & No. Obs. & \multicolumn{4}{|c|}{167,913} & \multicolumn{4}{|c|}{33,440} \\
\hline
\end{tabular}

In Table 5 the estimation results for the weighting factor $\frac{k}{h}$ and the strategic factor $s$ are shown for both the First Forecast sample and the Last Revision sample, for both time periods. The empirical results confirm what was to be expected. Before the new regulation was enforced, analysts strategically inflated their first forecast and deflated their last revision, which is in line with management pleasing behavior. After the 2002 regulation, which tackled conflicts of interest, the strategic behavior becomes insignificant. Overconfidence remains in both the pre and post time periods for both samples. This is additional empirical evidence that the overweighting of private information is indeed static overconfidence. Each analyst is overconfident in the sense that if he receives a signal, he overestimates its precision at any point in time.

\section{Conclusion}

This paper contributes to the literature in three ways. First, a two-stage model is developed where behavioral and strategic bias can coexist. Secondly, the model is tested on a large dataset of quarterly earnings forecasts and the empirical results confirm the coexistence of overconfidence and strategic incentives. Thirdly, this paper is the first, as we know of, to empirically investigate the difference in the decision making process between the first earnings forecast and the last earnings 
revision of financial analysts. Descriptive statistics as well as regression results suggest that financial analysts issue initial optimistic (less pessimistic) earnings forecasts. In their last revision, however, they tend to pessimistic (more pessimistic) earnings forecasts.

We provide empirical evidence on the decision process throughout the forecasting period. Our empirical findings show a consistent overweighting of private information throughout the forecasting period. A static overconfidence is present in the first forecast as well as in the last revision. Our results also show a strategic inflation of the forecast just after an earnings announcement followed by a strategic deflation of the earnings forecasts just before the next earnings announcement. Both the initial inflation and the final deflation are consistent with management pleasing theories. An initially inflated optimistic forecast stimulates buying behavior among investors, possibly pushing up the stock price and potentially making it an ideal moment for the management to sell their stock. A deflated forecast just before the announcement date creates beatable targets for management which can enjoy a higher return on their stock due to a favorable market reaction to the positive earnings surprise. The conflicts of interest financial analysts are confronted with, are often believed to imply a trade off between management pleasing or compensational benefits and forecast accuracy. Because the benefits outweigh the costs of a less accurate forecast, financial analysts engage in this management pleasing behavior. However, earnings forecasts formed under the earnings guidance of the management are shown to be more accurate (Hutton, 2005). Consequently, there is no more trade off for the financial analyst. On the contrary, the financial analyst seems to please all parties, investors and management, involved. Our empirical findings lead to the overall conclusion that overconfidence and strategic incentives coexist in financial analysts' earnings forecasts. 


\section{References}

[1] Abarbanell J. 1991. Do Analysts' Forecasts Incorporate Information in Prior Stock Price Changes? Journal of Accounting and Economics, Vol.14. pp 147165 .

[2] Barber B. M. and Odean T. 2001. Boys Will be Boys: Gender, Overconfidence, and Common Stock Investment. Quarterly Journal of Economics, Vol.116(1). pp 261-292.

[3] Bartov E.; Givoly D. and Hayn C. 2002. The Rewards to Meeting or Beating Earnings Expectations. NYU Working Paper.

[4] Brown D. 1997. Analyst Forecasting Errors: Additional Evidence. Financial Analysts Journal, Vol.53(6).

[5] Brown L. 2001. A Temporal Analysis of Earnings Surprises: Profits and Losses. Journal of Accounting Research, Vol.30(2).

[6] Byard D. and Shaw K. W. 2003. Corporate Disclosure Quality and Properties of Analysts' Information. Journal of Accounting, Auditing and Finance, Vol.18. pp 355-378.

[7] Cameron A. C.; Gelbach J. B. and Douglas L. M. 2006. Robust Inference With Multi-Way Clustering. Technical Working Paper Series, National Bureau of Economic Research, Massachusetts.

[8] Chen Q., Francis J. and Jiang W. 2005. Investor Learning about Analyst Predictive Ability. Journal of Accounting and Economics, Vol.39. pp 3-24.

[9] Chen Q. and Jiang W. 2006. Analysts' Weighting of Private and Public Information. Review of Financial Studies, Vol.19(1). pp 319-355.

[10] Chen S. and Matsumoto D. A. 2006. Favorable versus Unfavorable Recommendations: The Impact on Analyst Access to Management-Provided Information. Journal of Accounting Research, Vol.44(4). pp 657-689.

[11] Clarke J. and Subramanian A. 2006. Dynamic forecasting behavior by analysts: Theory and evidence. Journal of Financial Economics, Vol.80. pp 81-113. 
[12] Clement M. B. 1999. Analyst forecast accuracy: Do ability, resources, and portfolio complexity matter? Journal of Accounting and Economics, Vol.27. pp 285-303.

[13] Daniel K.; Hirshleifer D. and Subrahmanyam A. 1998. Investor Psychology and Security Market Under- and Overreactions. Journal of Finance, Vol.53(6). pp 1839-1885.

[14] Deaux K. and Farris E. 1977. Attributing Causes for One's Own Performance: The Effects of Sex, Norms, and Outcome. Journal of Research in Personality, Vol.11(1). pp 59-72.

[15] De Bondt W. and Thaler H. 1990. Do Security Analysts Overreact? American Economic Review, Vol.80(2). pp 52-57.

[16] Dugar A. and Nathan S. 1995. The Effect of Investment Banking Relationships on Financial Analysts' Earnings Forecasts and Investment Recommendations. Contemporary Accounting Research, Vol.12(1). pp 131-160.

[17] Easterwood C and Nutt R. 1999. Inefficiency in Analysts' Earnings Forecasts: Systematic Misreaction or Systematic Optimism? Journal of Finance, Vol.54(5). pp 1777-1797.

[18] Fischhoff B.; Slovic P and Lichtenstein S. 1977. Knowing with Certainty: The Appropriateness of Extreme Confidence. Journal of Experimental Psychology: Human Perception and Performance, Vol.3(4). pp 552-564.

[19] Francis J. and Philbrick D. 1993. Analysts' decisions as products of a multitask environment. Journal of Accounting Research, Vol.31. pp 137-164.

[20] Friesen G. C. and Weller P. A. 2006. Quantifying Cognitive Biases in Analyst Earnings Forecasts. Journal of Financial Markets, Vol.9. pp 333-365.

[21] Gervais S. and Odean T. 2001. Learning to be overconfident. Review of Financial Studies, Vol.14. pp 1-27.

[22] Green T.; Jegadeesh N. and Tang Y. 2007. Gender and Job Performance: Evidence from Wall Street. Working Paper. 
[23] Groysberg B.; Healy P. M. and Maber D. 2008. What Drives Sell-Side Analyst Compensation at High-Status Banks? Working Paper.

[24] Hayes R. 1998. The impact of trading commission incentives on analysts' stock coverage decisions and earnings forecasts. Journal of Accounting Research, Vol.36. pp 299-320.

[25] Healy P. M. and Wahlen J. M. 1999. A Review of the Earnings Management Literature and its Implications for Standard Setting. Accounting Horizons, Vol.13(4). pp 365-383.

[26] Hilary G. and Menzly L. 2006. Does Past Success Lead Analysts to Become Overconfident. Management Science, Vol.52(4). pp 489-500.

[27] Hong H. and Kubik J. 2003. Analyzing the Analysts: Career Concerns and Biased Earnings Forecasts. Rand Journal of Economics, Vol.31. pp 121-144.

[28] Hong, H.; Lim T. and Stein J. C. 2000. Bad News Travels Slowly: Size, Analysts Coverage, and Profitability of Momentum Strategies. Journal of Finance, Vol.55. pp 265-295.

[29] Hutton A. P. 2005. Determinants of Managerial Earnings Guidance Prior to Regulation Fair Disclosure and Bias in Analysts' Earnings Forecasts. Contemporary Accounting Research, Vol.22(4). pp 867-914.

[30] Kahneman D. and Riepe M. W. 1998. The Psychology of the Non-Professional Investor. Journal of Portfolio Management, Vol. 24(4). pp 52-65.

[31] Ljungqvist A.; Marston F.; Starks L. T.; Wei K. D. and Yan H. 2007. Conflicts of interest in sell-side research and the moderating role of institutional investors. Journal of Financial Economics, Vol.85(2). pp 420-456.

[32] Malmendier U. and Shanthikumar D. 2007. Do security analysts speak in two tongues? Working Paper.

[33] Matsumoto, D. A. 2002. Management's Incentives to Avoid Negative Earnings Surprises. The Accounting Review, Vol.77 (3).

[34] Markov S. and Tan M. 2006. Loss function asymmetry and forecast optimality: Evidence from individual analysts' forecasts. Working Paper. 
[35] McNichols M. and O'Brien P. 1997. Self selection and analyst coverage. Journal of Accounting Research, Vol.35. pp 167- 199.

[36] Michaely R. and Womack K. L. 1999. Conflict of Interest and the Credibility of Underwriter Analyst Recommendations. Review of Financial Studies, Vol.12(4). pp 653-686.

[37] O'Brian P. 1988. Analysts' forecasts as earnings expectations. Journal of Accounting and Economics, Vol.10. pp 53-83.

[38] Odean T. 1998. Are Investors Reluctant to Realize Their Losses? Journal of Finance, Vol.53(5). pp 1775-1798.

[39] Petersen M. A. 2008. Estimating standard errors in Finance Panel Data Sets: Comparing Approaches. Forthcoming, Review of Financial Studies.

[40] Ramnath S; Rock S. and Shane P. 2008. A Review of Research Related to Financial Analysts' Forecasts and Stock Recommendations. International Journal of Forecasting, Vol.24(1). pp 34-75.

[41] Richardson S. A.; Teoh S. H. and Wysocki P. D. 2004. The walkdown to beatable analyst forecasts: the roles of equity issuance and insider trading incentives. Contemporary Accounting Research, Vol.21 (4). pp 885-924.

[42] Schipper K. 1991. Analysts' forecasts. Accounting Horizons, Vol.5. pp 105-119.

[43] Shefrin H. 2008. A Behavioral Approach to Asset Pricing. Academic Press Advanced Finance Series.

[44] Shleifer A. 2000. Inefficient Markets: an introduction to behavioral finance. Oxford University Press.

[45] Skinner D. J. and Sloan R. G. 2002. Earnings Surprises, Growth Expectations, and Stock Returns or Don't Let an Earnings Torpedo Sink Your Portfolio. Review of Accounting Studies, Vol.7. pp 289-312.

[46] Sorescu S. and Subrahmanyam A. 2006. The Cross Section of Analyst Recommendations. Journal of Financial and Quantitative Analysis, Vol.41. pp 139-168. 
[47] Stickel S. E. 1992. Reputation and Performance among Security Analysts. Journal of Finance, Vol.47. pp 1811-1836.

[48] Thompson S. 2006. Simple Formulas for Standard Errors that Cluster by Both Firm and Time. Harvard Working Paper.

[49] White H. 1984. Asymptotic Theory for Econometricians. Academic Press.

[50] Zitzewitz E. 2001. Opinion-Producing Agents: Career Concerns and Exaggeration. Working Paper. 


\section{Appendix}

\section{Table 6: Correlation Matrix First Forecast sample}

This table presents the correlation between the variables from equation (8) for the First Forecast sample. The forecast error, the deviation from consensus and the earnings forecast are deflated by the share price.

\begin{tabular}{|c|c|c|c|c|c|c|c|c|c|}
\hline & $\mathrm{FE}$ & Dev & $\mathrm{f}$ & Age & Size & FirmExp & TotExp & FirmCompl & IndCompl \\
\hline $\mathrm{FE}$ & 1.00 & 0.05 & 0.04 & 0.02 & -0.05 & 0.00 & -0.01 & -0.01 & -0.01 \\
\hline Dev & & 1.00 & 0.41 & 0.34 & -0.06 & 0.01 & 0.03 & 0.00 & 0.04 \\
\hline f & & & 1.00 & -0.02 & 0.03 & 0.08 & 0.06 & 0.11 & -0.03 \\
\hline Age & & & & 1.00 & -0.04 & -0.01 & 0.03 & -0.08 & 0.07 \\
\hline Size & & & & & 1.00 & 0.21 & 0.09 & 0.12 & -0.10 \\
\hline FirmExp & & & & & & 1.00 & 0.60 & 0.17 & 0.02 \\
\hline TotExp & & & & & & & 1.00 & 0.21 & 0.12 \\
\hline FirmCompl & & & & & & & & 1.00 & 0.12 \\
\hline IndCompl & & & & & & & & & 1.00 \\
\hline
\end{tabular}

\section{Table 7: Correlation Matrix Last Revision sample}

This table presents the correlation between the variables from equation (8) for the Last Revision sample. The forecast error, the deviation from consensus and the earnings forecast are deflated by the share price.

\begin{tabular}{|c|c|c|c|c|c|c|c|c|c|}
\hline & $\mathrm{FE}$ & Dev & $\mathrm{f}$ & Age & Size & FirmExp & TotExp & FirmCompl & IndCompl \\
\hline $\mathrm{FE}$ & 1.00 & 0.02 & -0.12 & 0.02 & 0.00 & -0.01 & -0.01 & -0.03 & -0.01 \\
\hline Dev & & 1.00 & 0.25 & 0.34 & -0.07 & 0.00 & 0.01 & -0.10 & 0.02 \\
\hline $\mathrm{f}$ & & & 1.00 & -0.05 & -0.01 & 0.04 & 0.05 & 0.19 & 0.04 \\
\hline Age & & & & 1.00 & -0.03 & 0.00 & 0.01 & -0.10 & 0.00 \\
\hline Size & & & & & 1.00 & 0.17 & 0.08 & -0.01 & -0.07 \\
\hline FirmExp & & & & & & 1.00 & 0.67 & 0.10 & -0.05 \\
\hline TotExp & & & & & & & 1.00 & 0.11 & -0.01 \\
\hline FirmCompl & & & & & & & & 1.00 & 0.19 \\
\hline IndCompl & & & & & & & & & 1.00 \\
\hline
\end{tabular}




\section{Table 8: Summary Statistics}

This table presents the summary statistics of the forecast error, the deviation from consensus, the earnings forecast (deflated) and the control variables used in equation (8). Panel A shows the summary statistics of the First Forecast sample. Panel B shows the summary statistics of the Last Revision sample. Outliers are removed by deleting the top and bottom $0.1 \%$ for the variables forecast error, deviation and earnings forecast. The earnings forecast data is obtained from I/B/E/S.

\begin{tabular}{l|rrrr}
\hline Panel A & \multicolumn{4}{|c}{ First Forecast Sample } \\
\hline FE & \multicolumn{1}{|c}{ Mean } & Stdev. & \multicolumn{1}{c}{ Min. } & \multicolumn{1}{c}{ Max. } \\
Dev & $0.30 \mathrm{E}^{-5}$ & 0.006 & -0.254 & 0.682 \\
f & 0.014 & 0.009 & -0.112 & 0.532 \\
Age & 73.874 & 26.127 & 1.000 & 143.000 \\
Size & 7.930 & 1.324 & -5.319 & 12.344 \\
FirmExp & 11.461 & 10.363 & 1.000 & 59.000 \\
TotExp & 20.721 & 13.390 & 1.000 & 59.000 \\
FirmCompl & 9.223 & 5.889 & 1.000 & 67.000 \\
IndCompl & 1.716 & 0.937 & 1.000 & 9.000 \\
& \multicolumn{5}{|c}{} \\
\hline Panel B & \multicolumn{4}{|c}{ Last Revision Sample } \\
\hline & Mean & Stdev. & Min. & Max. \\
\hline FE & -0.001 & 0.004 & -0.101 & 0.383 \\
Dev & 0.004 & 0.008 & -0.050 & 0.109 \\
f & 0.015 & 0.010 & 0.000 & 0.191 \\
Age & 29.299 & 19.836 & 1.000 & 128.000 \\
Size & 8.679 & 1.282 & -3.744 & 12.431 \\
FirmExp & 13.086 & 11.321 & 1.000 & 59.000 \\
TotExp & 21.086 & 13.496 & 1.000 & 59.000 \\
FirmCompl & 4.642 & 4.157 & 1.000 & 32.000 \\
IndCompl & 1.175 & 0.441 & 1.000 & 5.000 \\
\hline
\end{tabular}

FE is the difference between the earnings forecast and the actual, deflated by the share price. Dev is the difference between the earnings forecast and the consensus forecast, deflated by the share price. f is the analyst's earnings forecast, deflated by the share price. Age is the number of days between the issue of the analyst's earnings forecast and the reporting date of the actual earnings. Size is the logarithm of the market capitalization. FirmExp is the number of quarters an analyst has followed a certain stock. TotExp is the number of quarters the analyst is present in the data set. For both ability variables data starting from 1992 is used to prevent all analysts from starting with the same experience in 1996. FirmCompl is the number of companies an analyst follows during a quarter. IndCompl is the number of sectors an analyst follows during a quarter. I/B/E/S identifies 11 sectors using a proprietary classification scheme for companies with similar business lines. 


\section{Table 9: Estimation Results for Single Issue and First of Revision}

This table presents estimation results for the Theoretical Model, expressed in equation (8). The second and third column show the coefficient estimates and t-values, respectively, for the Single Issue sample. The third and fourth column represent the coefficient estimates and t-values, respectively, for the First of Revision sample. For both regressions firm fixed effects is used with clustered standard errors by industry. These clustered standard errors are White (1984) standard errors adjusted to account for possible correlation within a cluster, i.e. industry. The earnings forecast data is obtained from I/B/E/S. ***,*** indicate significance at the $10 \%, 5 \%$ and $1 \%$ level, respectively. Coefficient estimates are multiplied by 1000 to facilitate readability.

\begin{tabular}{|c|c|c|c|c|c|c|}
\hline & \multicolumn{6}{|c|}{ Theoretical Model } \\
\hline \multirow{2}{*}{$\begin{array}{l}\text { Explanatory } \\
\text { Variables }\end{array}$} & \multicolumn{3}{|c|}{ Single Issue } & \multicolumn{3}{|c|}{ First of Revision } \\
\hline & \multirow{2}{*}{$\begin{array}{l}\text { Coeff. } \\
26.4177\end{array}$} & \multicolumn{2}{|c|}{ t-value } & \multirow{2}{*}{$\begin{array}{l}\text { Coeff. } \\
23.7026\end{array}$} & \multicolumn{2}{|c|}{ t-value } \\
\hline $\operatorname{Dev}(\widehat{\beta})$ & & 4.30 & $* * *$ & & 2.20 & $* *$ \\
\hline $\mathrm{f}(\widehat{\gamma})$ & 20.8574 & 1.38 & & 79.3088 & 4.14 & $* * *$ \\
\hline Age & $56.00 \mathrm{E}^{-4}$ & 4.13 & $* * *$ & $-85.00 \mathrm{E}^{-4}$ & -1.71 & * \\
\hline Size & $-21.78 \mathrm{E}^{-2}$ & -2.03 & $* *$ & $-26.00 \mathrm{E}^{-4}$ & -0.01 & \\
\hline FirmExp & $1.00 \mathrm{E}^{-4}$ & 0.05 & & $-97.00 \mathrm{E}^{-4}$ & -3.97 & $* * *$ \\
\hline TotExp & $-2.00 \mathrm{E}^{-4}$ & -0.17 & & $52.00 \mathrm{E}^{-4}$ & 2.46 & $* *$ \\
\hline FirmCompl & $-0.01 \mathrm{E}^{-4}$ & -0.02 & & $-49.00 \mathrm{E}^{-4}$ & -1.29 & \\
\hline IndCompl & $78.00 \mathrm{E}^{-4}$ & 0.87 & & $-53.50 \mathrm{E}^{-3}$ & -1.74 & * \\
\hline No. Obs. & \multicolumn{3}{|c|}{268,842} & \multicolumn{3}{|c|}{53,279} \\
\hline
\end{tabular}




\section{Table 10: Summary Statistics of the First Forecast and Last Revision Samples: Extended model}

This table presents the summary statistics of the variables Track Record, Star, Investment banking business and Trading volume, used in equation (10). Panel A shows the summary statistics of the First Forecast sample. Panel B shows the summary statistics of the Last Revision sample. Trading volume outliers are removed. The earnings forecast data is obtained from $\mathrm{I} / \mathrm{B} / \mathrm{E} / \mathrm{S}$. The security offerings data is retrieved from Westlaw Business, while the trading volume data was obtained from CRSP.

\begin{tabular}{|c|c|c|c|c|}
\hline Panel A & \multicolumn{4}{|c|}{ First Forecast Sample } \\
\hline & Min. & Mean & Max. & Stdev. \\
\hline TR & -1.000 & 0.312 & 1.000 & 0.531 \\
\hline Star & 0.000 & 0.031 & 1.000 & 0.174 \\
\hline IB & 0.000 & 0.066 & 1.000 & 0.249 \\
\hline TVol & 0.974 & 34.685 & 178.243 & 39.249 \\
\hline Panel B & \multicolumn{4}{|c|}{ Last Revision Sample } \\
\hline & Min. & Mean & Max. & Stdev. \\
\hline TR & -1.000 & 0.238 & 1.000 & 0.502 \\
\hline Star & 0.000 & 0.036 & 1.000 & 0.186 \\
\hline IB & 0.000 & 0.057 & 1.000 & 0.232 \\
\hline TVol & 2.995 & 67.537 & 273.304 & 64.885 \\
\hline
\end{tabular}

TR measures the frequency of the analysts' earnings forecast being more accurate than the consensus forecast up until time $t$ for firm $k$. Star is a dummy variable which equals one when an analyst has been elected by the Institutional Investor all-American research Teams poll. IB is a dummy variable which equals one when an analyst is employed by a brokerage house which has assisted as underwriter in a public offering of the company, for which the analyst is following the stock. The window of affiliation is five years, centered around the moment of the registration with the SEC of the public offering. TVol is the average daily number of shares traded the previous quarter multiplied by the average daily price of the previous quarter. 


\section{Table 11: Estimation Results Extended Model}

This table presents estimation results for the Extended Model, expressed in equation (10). The second and third column show the coefficient estimates and t-values, respectively, using analysts' first earnings forecast. The third and fourth column represent the coefficient estimates and t-values, respectively, using analysts' last earnings review. For both regressions firm fixed effects is used with clustered standard errors by industry. These clustered standard errors are White (1984) standard errors adjusted to account for possible correlation within a cluster, i.e. industry. The earnings forecast data is obtained from I/B/E/S. *,***** indicate significance at the $10 \%, 5 \%$ and $1 \%$ level, respectively. Coefficient estimates are multiplied by 1000 to facilitate readability.

\begin{tabular}{|c|c|c|c|c|c|c|}
\hline & \multicolumn{6}{|c|}{ Extended Model } \\
\hline \multirow{2}{*}{$\begin{array}{l}\text { Explanatory } \\
\text { Variables }\end{array}$} & \multicolumn{3}{|c|}{ First Forecast } & \multicolumn{3}{|c|}{ Last Revision } \\
\hline & \multirow{2}{*}{$\frac{\text { Coeff. }}{292427}$} & \multicolumn{2}{|c|}{ t-value } & \multirow{2}{*}{$\begin{array}{l}\text { Coeff. } \\
35.2233\end{array}$} & \multicolumn{2}{|c|}{ t-value } \\
\hline Dev & & 4.08 & $* * *$ & & 4.78 & $* * *$ \\
\hline Dev $\times \mathrm{TR}$ & -10.5412 & -1.27 & & -15.6722 & -2.04 & $* *$ \\
\hline Dev $\times$ Star & -9.8813 & -0.75 & & -54.5693 & -1.74 & $*$ \\
\hline $\mathrm{f}$ & 19.5337 & 1.28 & & -56.8933 & -2.83 & $* * *$ \\
\hline $\mathrm{f} \times \mathrm{IB}$ & 5.4582 & 0.36 & & $-42.23 \mathrm{E}^{-2}$ & -0.10 & \\
\hline $\mathrm{f} \times \mathrm{TVol}$ & $31.68 \mathrm{E}^{-2}$ & 2.05 & $* *$ & $13.78 \mathrm{E}^{-2}$ & 1.46 & \\
\hline Age & $47.00 \mathrm{E}^{-4}$ & 2.98 & $* * *$ & $-8.00 \mathrm{E}^{-4}$ & -0.33 & \\
\hline Size & $-32.39 \mathrm{E}^{-2}$ & -2.88 & $* * *$ & $8.52 \mathrm{E}^{-2}$ & 0.48 & \\
\hline FirmExp & $-20.00 \mathrm{E}^{-4}$ & -1.06 & & $-24.00 \mathrm{E}^{-4}$ & -1.52 & $*$ \\
\hline TotExp & $5.00 \mathrm{E}^{-4}$ & 0.48 & & $-5.00 \mathrm{E}^{-4}$ & -0.54 & \\
\hline FirmCompl & $1.00 \mathrm{E}^{-4}$ & 0.09 & & $5.00 \mathrm{E}^{-4}$ & 0.12 & \\
\hline IndCompl & $27.00 \mathrm{E}^{-4}$ & 0.30 & & $-24.00 \mathrm{E}^{-4}$ & -0.12 & \\
\hline Adj. $R^{2}$ & \multicolumn{3}{|c|}{$0.52 \%$} & \multicolumn{3}{|c|}{$1.09 \%$} \\
\hline No. Obs. & \multicolumn{3}{|c|}{322,123} & \multicolumn{3}{|c|}{60,047} \\
\hline
\end{tabular}


Table 12: Weighting and Strategic Factors for the Extended Model

This Table presents the weighting and strategical factors for specific values of the added covariates TR, Star, IB and TVol from equation (10). This analysis is performed ceteris paribus: when for example Star changes from 0 to 1 , the other covariates are kept at their mean value. The estimates of $\frac{k}{h}$ and $s$ are obtained using equation (11). The standard error are calculated using the delta method. For all factors the two sided hypothesis test of whether they are significantly different from 1 is performed. $*{ }^{* *},{ }^{* * *}$ indicate significance at the $10 \%, 5 \%$ and $1 \%$ level, respectively.

Weighting Factor

\begin{tabular}{|c|c|c|c|c|c|c|c|c|c|c|}
\hline & \multicolumn{5}{|c|}{ First Forecast } & \multicolumn{5}{|c|}{ Last Revision } \\
\hline Covariates & values & $\frac{k}{h}$ & $S E\left(\frac{\widehat{k}}{h}\right)$ & \multicolumn{2}{|c|}{ t-value } & values & $\frac{k}{h}$ & $S E\left(\frac{\widehat{k}}{h}\right)$ & \multicolumn{2}{|c|}{ t-value } \\
\hline \multirow[t]{5}{*}{$T R$} & -1 & 1.04 & 0.0146 & 2.82 & *** & -1 & 1.05 & 0.0148 & 3.47 & *** \\
\hline & 0 & 1.03 & 0.0074 & 4.01 & $* * *$ & 0 & 1.03 & 0.0075 & 4.60 & *** \\
\hline & 0.31 & 1.03 & 0.0064 & 4.14 & $* * *$ & 0.24 & 1.03 & 0.0065 & 4.66 & $* * *$ \\
\hline & 0.69 & 1.02 & 0.0065 & 3.40 & $* * *$ & 0.56 & 1.03 & 0.0063 & 4.02 & *** \\
\hline & 1 & 1.02 & 0.0078 & 2.42 & $* * *$ & 1 & 1.02 & 0.0077 & 2.32 & $* * *$ \\
\hline \multirow[t]{2}{*}{ Star } & 0 & 1.03 & 0.0065 & 4.07 & $* * *$ & 0 & 1.03 & 0.0068 & 4.80 & $* * *$ \\
\hline & 1 & 1.02 & 0.0122 & 1.34 & & 1 & 0.98 & 0.0113 & -1.99 & $* *$ \\
\hline \multicolumn{11}{|c|}{ Strategic Factor } \\
\hline & \multicolumn{5}{|c|}{ First Forecast } & \multicolumn{5}{|c|}{ Last Revision } \\
\hline Covariates & values & $\widehat{s}$ & $S E(\widehat{s})$ & t-valu & & values & $\widehat{s}$ & $S E(\widehat{s})$ & t-value & \\
\hline \multirow[t]{2}{*}{$I B$} & 0 & 1.03 & 0.0148 & 2.19 & $* * *$ & 0 & 0.95 & 0.0130 & -3.59 & $* * *$ \\
\hline & 1 & 1.04 & 0.0233 & 1.64 & $*$ & 1 & 0.95 & 0.0196 & -2.41 & $* * *$ \\
\hline \multirow[t]{5}{*}{ TVol } & 0.97 & 1.02 & 0.0164 & 1.29 & & 2.99 & 0.94 & 0.0140 & -3.92 & $* * *$ \\
\hline & 6.77 & 1.02 & 0.0160 & 1.44 & & 18.62 & 0.95 & 0.0132 & -4.01 & $* * *$ \\
\hline & 34.69 & 1.03 & 0.0149 & 2.19 & $* *$ & 67.54 & 0.95 & 0.0131 & -3.58 & $* * *$ \\
\hline & 48.03 & 1.03 & 0.0149 & 2.51 & $* * *$ & 97.09 & 0.96 & 0.0147 & -2.91 & \\
\hline & 178.24 & 1.03 & 0.0293 & 2.91 & $* * *$ & 273.30 & 0.98 & 0.0371 & -0.52 & \\
\hline
\end{tabular}




\section{Table 13: Random Draw from First Forecast Sample}

This table presents estimation results for the Theoretical Model, expressed in equation (8). The second and third column show the coefficient estimates and t-values, respectively, using analysts' first earnings forecast. The sample used contains 60,047 observations, randomly drawn from the First Forecast sample of 322,123 observations. Firm fixed effects is used with clustered standard errors by industry. These clustered standard errors are White (1984) standard errors adjusted to account for possible correlation within a cluster, i.e. industry. The earnings forecast data is obtained from I/B/E/S. *,**,*** indicate significance at the $10 \%, 5 \%$ and $1 \%$ level, respectively. Coefficient estimates are multiplied by 1000 to facilitate readability.

The last two rows of this Table presents estimation results for the weighting factor $\frac{k}{h}$ and the strategic factor $s$, defined in equation (7). To determine the standard errors of the weighting and strategic factor the delta method is used. For both factors the two sided hypothesis test of whether they are significantly different from 1 is performed. $* * *, * * *$ indicate significance at the $10 \%, 5 \%$ and $1 \%$ level, respectively.

\begin{tabular}{l|rrll}
\multirow{2}{*}{$\begin{array}{l}\text { Explanatory } \\
\text { Variables }\end{array}$} & \multicolumn{4}{|c}{ Random Draw } \\
\cline { 2 - 5 } Dev $(\widehat{\beta})$ & \multicolumn{1}{|c}{ Coeff. } & t-value & \\
$\mathrm{f}(\widehat{\gamma})$ & 26.8406 & 2.61 & $* * *$ & \\
Age & 30.3184 & 2.07 & $* *$ & \\
Size & $19.00 \mathrm{E}^{-4}$ & 0.90 & & \\
FirmExp & $-76.20 \mathrm{E}^{-3}$ & -0.63 & & \\
TotExp & $-33.00 \mathrm{E}^{-4}$ & -1.17 & & \\
FirmCompl & $-15.00 \mathrm{E}^{-4}$ & -0.99 & & \\
IndCompl & $8.00 \mathrm{E}^{-4}$ & 0.27 & & \\
\hline No. Obs. & $85.00 \mathrm{E}^{-4}$ & 0.54 & & \\
\hline \hline & \multicolumn{5}{|c}{60,047} & & \\
\hline$\widehat{k}$ & Coeff. & SE & t-value \\
$\widehat{\widehat{s}}$ & 1.03 & 0.0109 & 2.54 & $* * *$ \\
\hline
\end{tabular}




\section{Table 14: Estimation Results with Median Consensus}

This table presents estimation results for the Theoretical Model, expressed in equation (8). Public information is proxied by the median consensus. The second and third column show the coefficient estimates and t-values, respectively, using analysts' first earnings forecast. The third and fourth column represent the coefficient estimates and t-values, respectively, using analysts' last earnings review. For both regressions firm fixed effects is used with clustered standard errors by industry. These clustered standard errors are White (1984) standard errors adjusted to account for possible correlation within a cluster, i.e. industry. The earnings forecast data is obtained from I/B/E/S. $*, * *, * * *$ indicate significance at the $10 \%, 5 \%$ and $1 \%$ level, respectively. Coefficient estimates are multiplied by 1000 to facilitate readability.

The last two rows of this Table presents estimation results for the weighting factor $\frac{k}{h}$ and the strategic factor $s$, defined in equation (7). To determine the standard errors of the weighting and strategic factor the delta method is used. For both factors the two sided hypothesis test of whether they are significantly different from 1 is performed. $* * *, * * *$ indicate significance at the $10 \%, 5 \%$ and $1 \%$ level, respectively.

\begin{tabular}{|c|c|c|c|c|c|c|c|c|}
\hline & \multicolumn{8}{|c|}{ Theoretical Model } \\
\hline \multirow{2}{*}{$\begin{array}{l}\text { Explanatory } \\
\text { Variables }\end{array}$} & \multicolumn{4}{|c|}{ First Forecast } & \multicolumn{4}{|c|}{ Last Revision } \\
\hline & \multicolumn{4}{|c|}{ Coeff. $\quad$ t-value } & Coeff. & \multicolumn{3}{|c|}{ t-value } \\
\hline $\operatorname{Dev}(\widehat{\beta})$ & 23.7222 & 3.99 & $* * *$ & & 28.1123 & 4.35 & $* * *$ & \\
\hline $\mathrm{f}(\widehat{\gamma})$ & 29.9351 & 2.18 & $* *$ & & -47.5742 & -3.03 & $* * *$ & \\
\hline Age & $50.00 \mathrm{E}^{-4}$ & 3.07 & $* * *$ & & $-8.00 \mathrm{E}^{-4}$ & -0.31 & & \\
\hline Size & $-19.97 \mathrm{E}^{-2}$ & -1.83 & $*$ & & $20.12 \mathrm{E}^{-2}$ & 1.56 & & \\
\hline FirmExp & $-17.00 \mathrm{E}^{-4}$ & -0.95 & & & $-27.00 \mathrm{E}^{-4}$ & -1.69 & * & \\
\hline TotExp & $8.00 \mathrm{E}^{-4}$ & 0.66 & & & $-5.00 \mathrm{E}^{-4}$ & -0.46 & & \\
\hline FirmCompl & $-8.00 \mathrm{E}^{-4}$ & -0.49 & & & $-3.00 \mathrm{E}^{-4}$ & -0.08 & & \\
\hline IndCompl & $-6.00 \mathrm{E}^{-4}$ & -0.07 & & & $-72.00 \mathrm{E}^{-4}$ & -0.36 & & \\
\hline \multirow[t]{2}{*}{ No. Obs. } & \multicolumn{4}{|c|}{322,121} & \multicolumn{4}{|c|}{60,046} \\
\hline & Coeff. & $\mathrm{SE}$ & t-val & & Coeff. & $\mathrm{SE}$ & t-valu & \\
\hline$\frac{\widehat{k}}{h}$ & 1.02 & 0.0062 & 3.89 & $* * *$ & 1.03 & 0.0068 & 4.22 & $* * *$ \\
\hline$\widehat{s}$ & 1.03 & 0.0149 & 2.12 & $* *$ & 0.95 & 0.0147 & -3.18 & $* * *$ \\
\hline
\end{tabular}




\section{Table 15: Estimation Results Pre and Post 2002}

This Table presents the estimated coefficients of Dev and f from equation (8). Estimation results are shown for both the First Forecast sample and the Last Revision sample. Results are presented separately for two periods of time. The pre 2002 and the post 2002 period. The cut off point is the second quarter of the year 2002. The pre period runs from January 1996 until April 2002 and the post period runs from April 2002 until December 2006. For all four regressions firm fixed effects is used with clustered standard errors by industry. These clustered standard errors are White (1984) standard errors adjusted to account for possible correlation within a cluster, i.e. industry. The earnings forecast data is obtained from I/B/E/S. *,***** indicate significance at the $10 \%, 5 \%$ and $1 \%$ level, respectively. Coefficient estimates are multiplied by 1000 and control variables are not reported to facilitate readability.

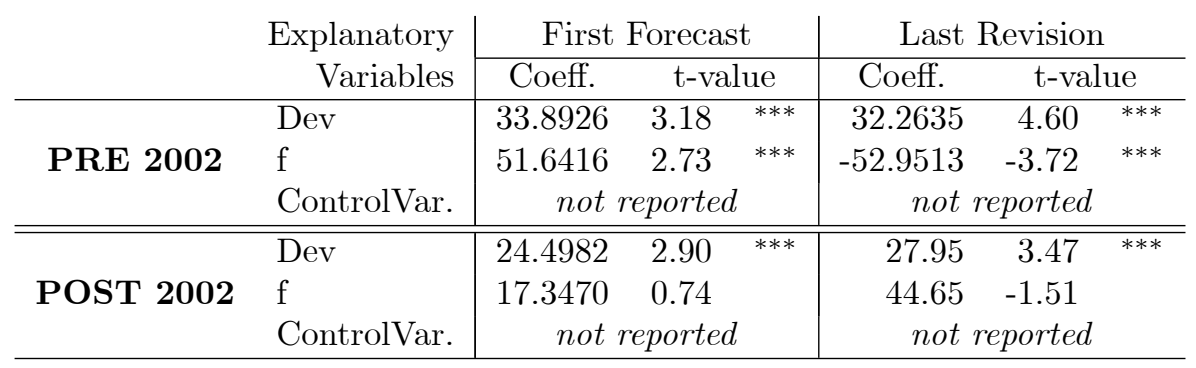

